\title{
Studies of Molybdenum Surface Modification for Growth of Adherent CVD Diamond Film
}

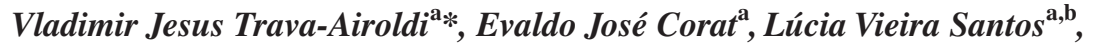 \\ João Roberto Moroc, Nélia Ferreira Leite ${ }^{\text {a }}$ \\ anstituto Nacional de Pesquisas Espaciais, INPE, São José dos Campos - SP, Brazil \\ ' Instituto Tecnológico de Aeronáutica, ITA/CTA, São José dos Campos - SP, Brazil \\ ${ }^{\mathrm{c}}$ Universidade São Francisco, USF, Itatiba - SP, Brazil
}

Received: January 02, 2002; Revised: September 30, 2002

\begin{abstract}
Surfaces with very poor mechanical and frictional properties can be improved, or even, acquire new properties similar to diamond if good adherent CVD diamond film is obtained on it. In this work, nitrogen ions were sub-implanted on pure molybdenum as a means to enhance CVD diamond film adherence. Deposition time from 2 up to $60 \mathrm{~h}$ were used for deposition of 10 to $400 \mu \mathrm{m}$ thick CVD diamond films with very good adherence on sub-implanted molybdenum substrate. Characterizations were carried out by XPS, X-ray diffraction and nano indentation on prepared surfaces prior to diamond growth and after the onset nucleation. The ionic sub-implantation with nitrogen possibly assists in adhesion, with the creation of a thin layer of nitrates and complexes.
\end{abstract}

Keywords: CVD Diamond, surface modification, ion sub-implantation, thin film

\section{Introduction}

The interest in diamond coating technology specifically on pre-shaped parts and synthesis of freestanding shapes of diamond has increased worldwide especially because of vast and exotic applications ${ }^{1-5}$. CVD diamond is far beyond the traditional technology, and it has been deposited on a variety of substrates, including metals, refractory metals, semiconductors and ceramics. Applications are widespread on several areas, and new applications are continuously proposed, even for the applications categorized as advantageous substitution of traditional products. The novelty products are the ones only possible due to the advent of CVD diamond technology. CVD diamond coated cutting tools, heat sinks, abrading devices, special optical coatings, substrates for multichip modules technology (MCM), electron field emitters and electrodes for electrochemical uses, is only a small list of interesting area of exploration. In the development of these application areas, there is much interest in understanding the mechanism and the role of the interface between the film and substrate concerning the adhesion process and, a lot of effort has been spent to understand the ef- fect of intrinsic and extrinsic stresses involving diamond and DLC films on different kinds of substrate materials ${ }^{6,7}$. More specifically, adherence between CVD diamond film and metallic substrate represent, for many research groups, the challenge to overcome. The main problems are related to difference in thermal expansion coefficient and adherence between the substrate and the diamond film. Using different kind of surface preparation and intermediate interface, good adherence between CVD diamond and WC-Co, $\mathrm{Si}_{3} \mathrm{~N}_{4}, \mathrm{SiC}$, and others ${ }^{1,8,9}$ have been obtained with relatively success in order to improve the lifetime of different kind of tools. Stainless steel and tool steel have been tried as a permanent substrate for CVD diamond growth, where, at the first time, the sub-implantation was mentioned ${ }^{9}$ as a surface preparation technique. Nitride films are known as a diffusion barriers in microelectronics devices and as well as superconductors ${ }^{10}$. Synthesis and analysis of molybdenum nitrites formed during ion implantation were investigated by some authors in order to improve molybdenum tribologycal properties and to understand the complexes formed $^{11,12}$.

*e-mail: vladimir@las.inpe.br 
In this work, concerning carbon diffusion during growth, the improvement of the adherence of the diamond film on molybdenum has been studied as a function of the surface modification by nitrogen ion implantation and deposition time in order to get thick diamond films. The adherence between them depends on how properly the interface is prepared. In this case very thin interface between diamond and metal was studied in order to avoid carbon diffusion onto the bulk of the substrate at diamond growth conditions, and also, for improving the chemical bond between the film and the substrate.

\section{Experiment}

Molybdenum rods of $1.6 \mathrm{~mm}$ diameter and $20 \mathrm{~mm}$ long were polished using diamond powder of $0.25 \mu \mathrm{m}$ grit and slurred in $n$-hexane ultrasonic bath $(1 \mathrm{~g} / 20 \mathrm{ml})$ during $60 \mathrm{~min}$ and annealed in $\mathrm{H}_{2}$ prior to DC discharge nitrogen ion subimplantation.

The experimental apparatus for nitrogen sub-implantation consists of a conventional DC discharge with special geometry of the electrodes. A conventional hot filament reactor with convenient substrate holder, as it is shown in Fig. 1, was used for diamond film growth.

Nitrogen and hydrogen mixtures were used in the DC discharge to produce a thin-nitrated layer by ion sub-implantation. The best set of parameters was found according to the best adherence after diamond deposition. Diamond deposition was carried out with conventional mixtures of $2 \%$ vol. $\%$ of $\mathrm{CH}_{4}$ in $\mathrm{H}_{2}$. The total gas flow rate was fixed at $100 \mathrm{sccm}$ and the pressure inside the reactor was maintained at 50 torr. The $850{ }^{\circ} \mathrm{C}$ substrate temperature was measured by a thermocouple, and from 2 up to $60 \mathrm{~h}$ deposition time was used for deposition of 10 to $400 \mu \mathrm{m}$ thick CVD diamond films, without delaminating.

Small angle X-ray Diffraction was performed in the nitrated molybdenum and nitrated molybdenum after $10 \mathrm{~min}$ of diamond nucleation. The XPS analysis was made on the molybdenum surface for all sets of samples.

In order to get good nano-indentation tests, only the $10 \mu \mathrm{m}$ thick films grown in pure and nitrated molybdenum were used.

\section{Results and Discussions}

Experiments have shown that higher temperature helped to improve the film adhesion, but it was not sufficient to avoid the film peeling off from the substrate after growing. An optimization of the sub-implantation parameters have been made in order to keep the integrity of the molybdenum structure during all sub-implantation process at temperatures ranging from 500 to $600{ }^{\circ} \mathrm{C}$ and, to increase the film adhesion. We found that good film quality and high nucleation density are reached at temperatures as high as (a)

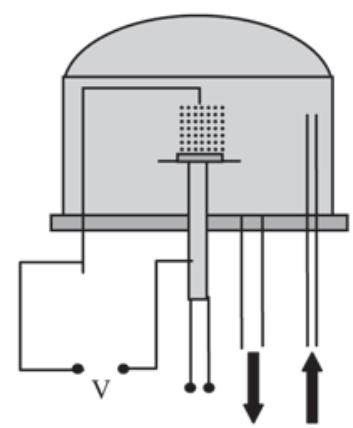

(b)

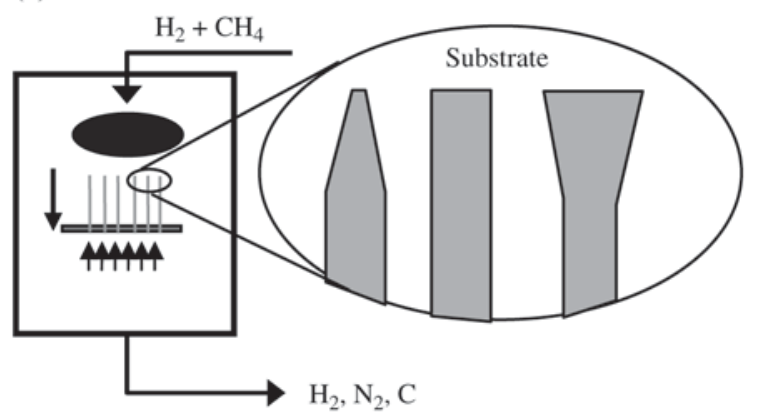

Figure 1. Experimental diagrams: a) DC discharge; b) diamond growth reactor

$850{ }^{\circ} \mathrm{C}$, for films grown up to $400 \mu \mathrm{m}$ thick during $60 \mathrm{~h}$ nitrated molybdenum substrate. In this work the best condition for nitrogen ion implantation was reached using nitrogen $20 \%$ vol. in hydrogen and at $600 \mathrm{~V}$ DC discharge.

Small angle X-ray Diffraction was performed in order to understand surface modification and how the most probable mechanism interferes on diamond adherence to the molybdenum surface when nitrogen ion-sub-implantation occurs. The results of pure molybdenum, nitrated molybdenum and nitrated molybdenum after $10 \mathrm{~min}$ of diamond nucleation are shown in Fig. 2. The apparent molybdenum nitride peaks give us the evidence of the surface modification for the nitrated molybdenum. The spectrum of a substrate after submitted to 10 min diamond nucleation shows the evident mixture of the molybdenum nitrides and carbides. However, the X-ray analysis is not sensitive to other complexes formed during the sub-implantation.

Our first attempt to observe the existence of such complexes was by using XPS analysis. Fig. 3a shows the analysis from nitrated molybdenum surface prepared for diamond growth. The binding energy around 227 and $232 \mathrm{eV}$ are the evidence of nitrides and oxides formation. In Fig. $3 \mathrm{~b}$ the peaks around 396 and $412 \mathrm{eV}$ correspond to surface compounds with nitrogen and oxygen, respectively. Again, one 

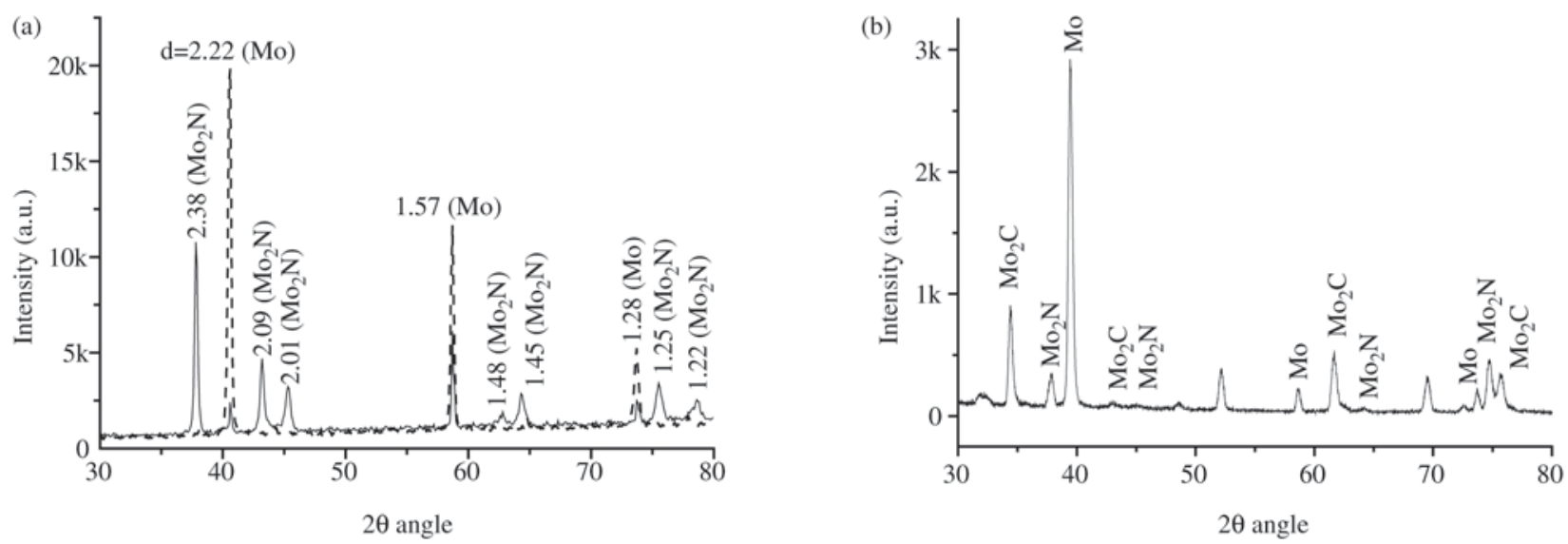

Figure 2. Small angle X-ray Diffraction for: a) pure molybdenum (continuous line) and nitrated molybdenum (dashed line); b) nitrated molybdenum surface after 10 min diamond onset nucleation.
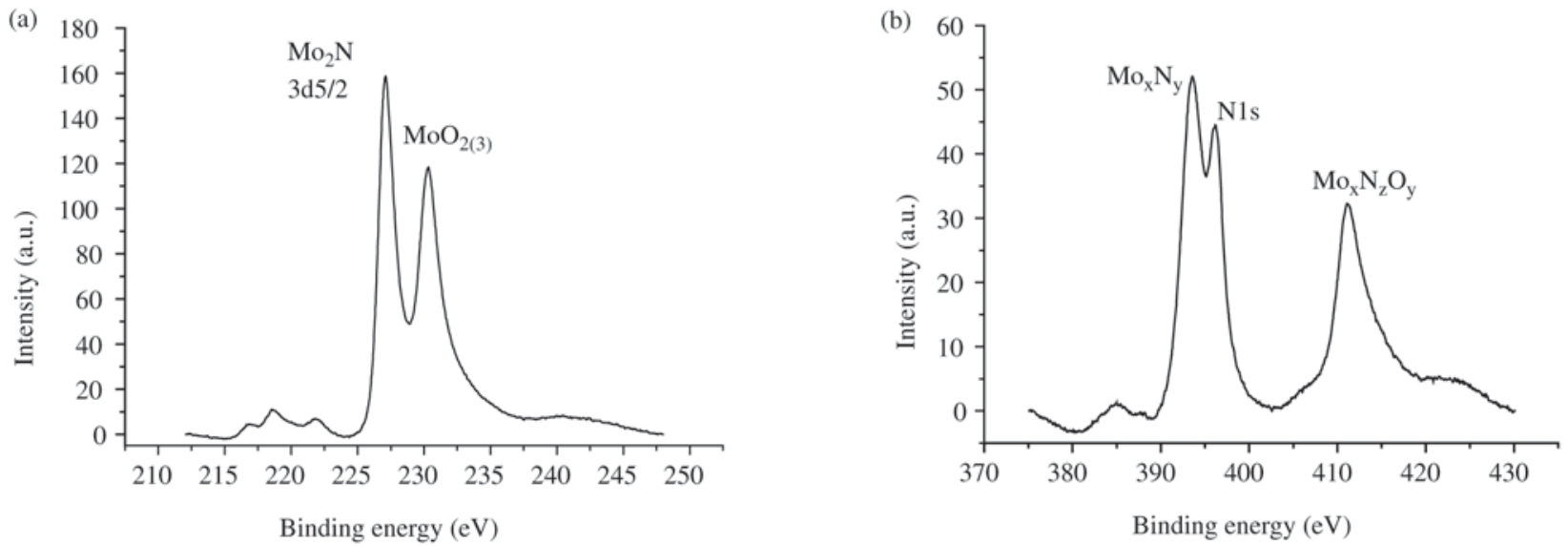

Figure 3. XPS analysis characterization for nitrated molybdenum: a) molybdenum nitrides and oxides; b) complexes with nitrogen and oxygen.
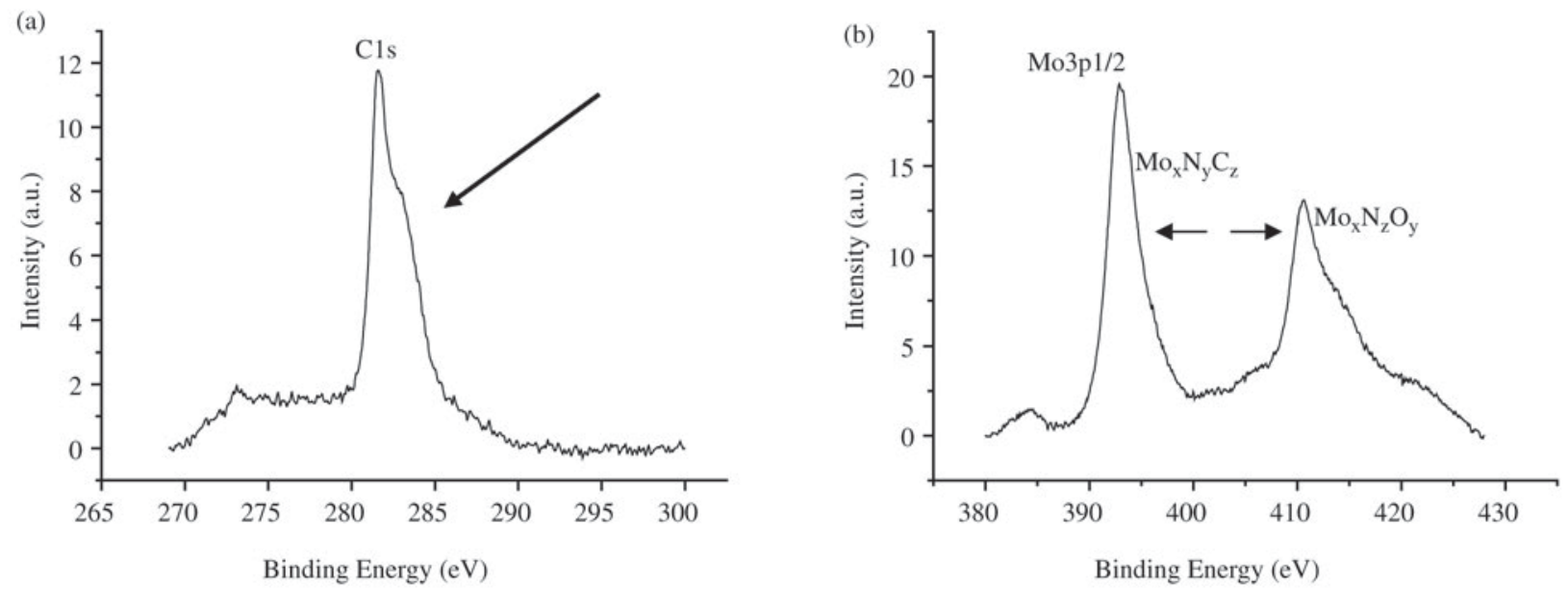

Figure 4. XPS analysis characterization for nitrated molybdenum after 10 min diamond growth: a) shifted and asymmetric binding energy peak for the carbon; b) shifted and asymmetric binding energy peaks for molybdenum complexes. 
can speculate that even complexes can be formed on molybdenum surface from ion bombardment and contribute to form a barrier against carbon diffusion during diamond growth process. In order to see the influence of this barrier, XPS analysis were carried out on substrate-cleaned surface after 10 min diamond nucleation. It is observed again the evidence of complex compounds now involving carbon atoms, characterized by the shifted and asymmetric binding energy peaks centered at 393 and $411 \mathrm{eV}$, as shown in Fig. 4a. In Fig. 4b the C1s peak, binding energy centered at $282 \mathrm{eV}$, depicts a strong asymmetry that corroborates the idea of a complex compound formation.

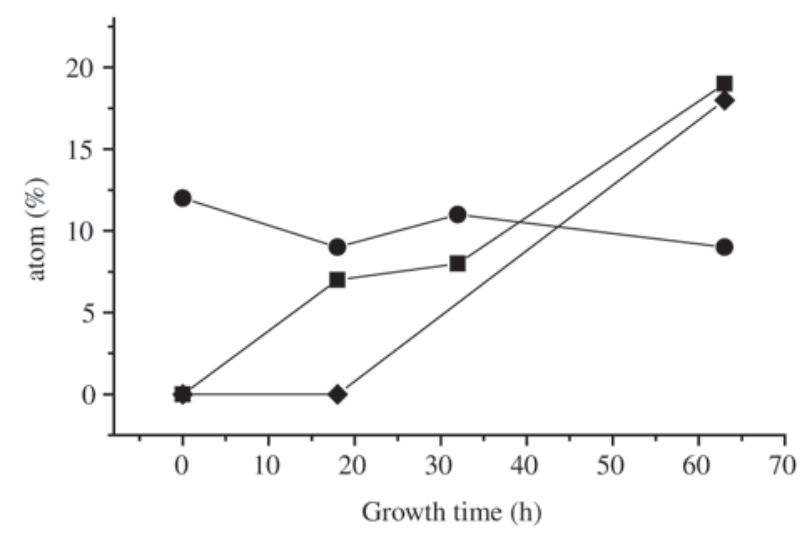

Figure 5. Change of $\mathrm{C}$ and $\mathrm{N}$ content on nitrated molybdenum surface and $\mathrm{C}$ content on nitrated molybdenum bulk as a function of the growth time. (-) \% atom on $\mathrm{N}$ on nitrated molybdenum surface; (ם) \% atom $\mathrm{C}$ on nitrated molybdenum surface; $(\checkmark) \%$ atom on $\mathrm{C}$ on nitrated molybdenum bulk.

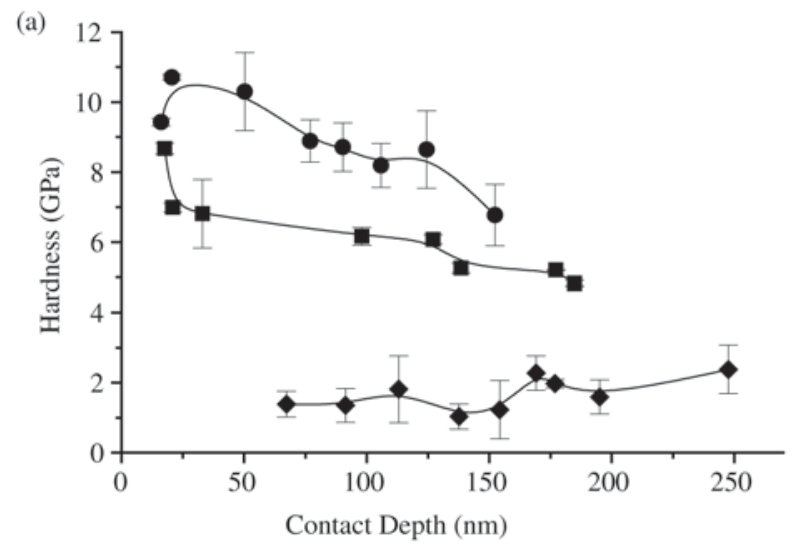

Figure 5 shows the change of $\mathrm{C}$ and $\mathrm{N} \%$ content on nitrated molybdenum surface and $\mathrm{C} \%$ content on nitrite molybdenum bulk as a function of the growth time. We can see that the $\mathrm{N} \%$ content is almost independent of the growth time, the $\mathrm{C}$ content increase on nitrite molybdenum surface with the growth time but in the molybdenum bulk, the $\mathrm{C} \%$ content remains constant as long as for $20 \mathrm{~h}$ of growth, indicating that the complex barrier help to avoid the diffusion of the carbon to the bulk of the substrate.

It is observed from Fig. 6a, that the bulk hardness is higher for samples with nitrated surface prior to diamond growth conditions, and it decrease when submitted to $10 \mathrm{~min}$ diamond growth conditions, but it is still high and keep the same behavior. The hardness is higher in the surface and decrease up to a depth of $150 \mathrm{~nm}$. Substrates without nitrogen sub-implantation and submitted to $10 \mathrm{~min}$ diamond growth condition has lower hardness and it doesn't exhibit hardness variation as function of the depth. Also, the stiffness (Fig. 6b) has been analyzed for the same samples. Samples with nitrogen sub-implantation exhibit dependence with the depth, while only a small variation of the stiffness was observed for samples without nitrogen sub-implantation. These results confirm that a barrier for carbon diffusion could be formed when nitrogen sub-implantation is used, indicating a surface modification.

Using this results, diamond thin and thick film have been obtained on molybdenum submitted to nitrogen sub-implantation with very good adherence even at growth temperature as low as $700{ }^{\circ} \mathrm{C}$, and different kind of devices have been developed. Examples of these devices are the diamond burr used in very high rotation, as higher as $400.000 \mathrm{rpm}$, and in high-energy ultrasound application. The lifetime of these devices is over than 30 times larger than conventional one. Figure 7 shows some examples of mentioned devices.

Figure 6. Nano Indentation showing a) surface hardness; b) stiffness of ( $\bullet 10$ min diamond growth on molybdenum, $(\bullet)$ nitrated molybdenum and (অ) 10 min diamond growth on nitrite molybdenum as function of penetration depth.

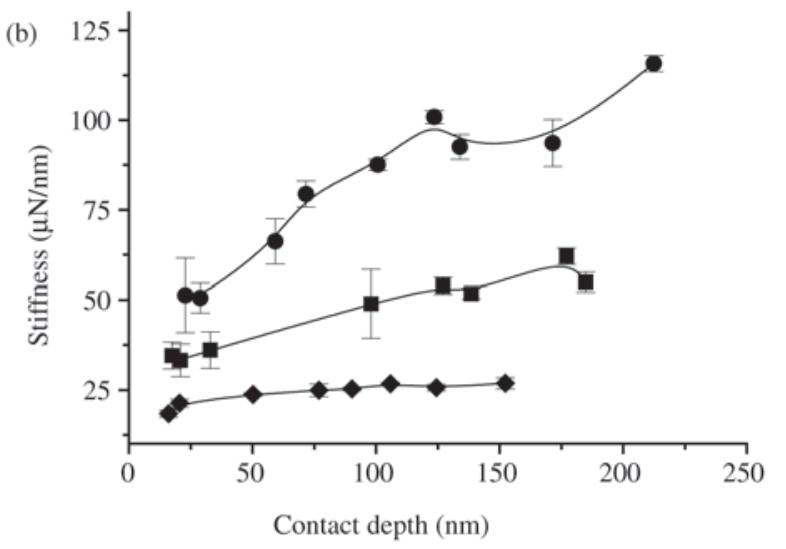



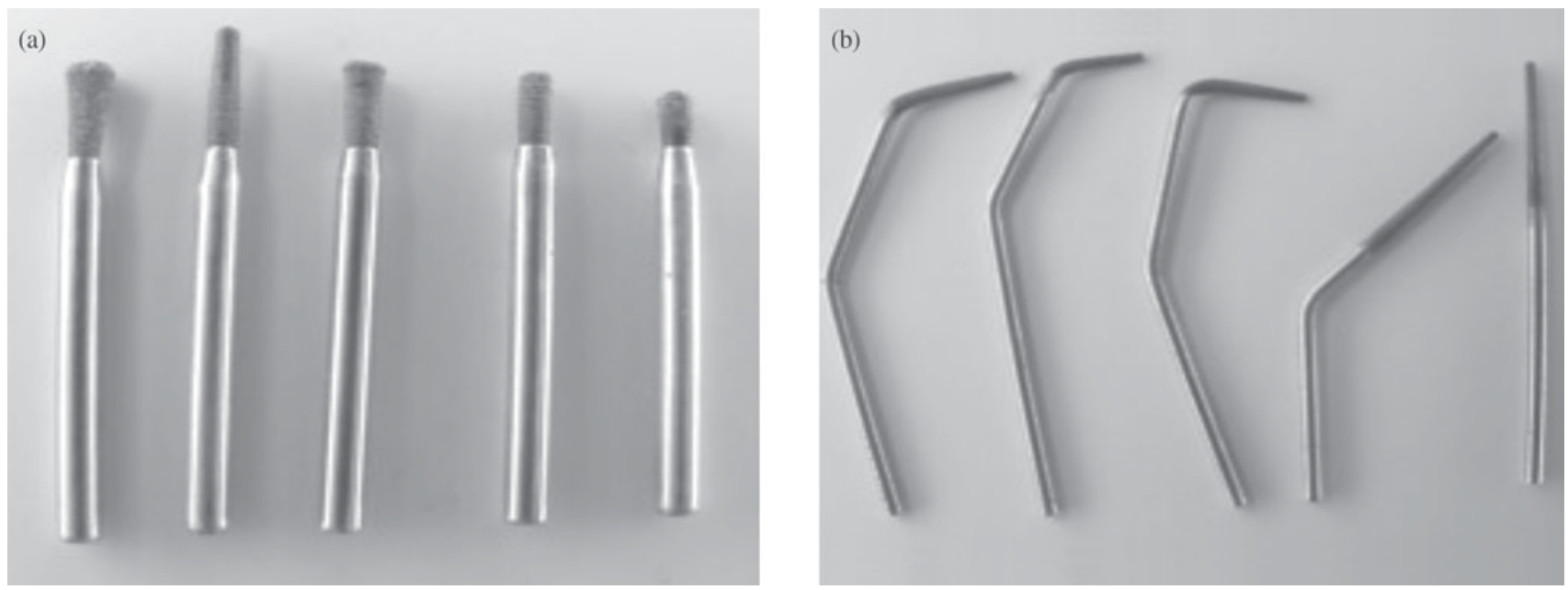

Figure 7. Examples of devices developed with molybdenum surface modification, a) Diamond burr used in very high rotation; b) used in high-energy ultrasound equipment.

\section{Conclusion}

Ions sub-implantation on molybdenum has been presented as a good way to obtain good adherence with CVD diamond. Nano indentation, small angle X-ray diffraction and XPS analysis show an evidence of surface modification by the formation of nitrogen and carbon complexes. This surface modification was efficient in inhibiting carbon diffusion during the diamond growth process keeping the mechanical properties of the substrate. Also, these complexes contribute to improve the adherence of diamond to the modified molybdenum surface. Examples, as diamond burr, of very adherent diamond thick film on modified molybdenum surface confirm the success of these studies.

\section{Acknowledgements}

The authors are very grateful to FAPESP and CNPq for financial support, Nilson Cristino da Cruz and Elidiane Cipriano Rangel for nano indentation analysis, and Eduardo Abramof for X-ray analysis.

\section{References}

1. Busch, J.V.; Dismukes, J.P. “A comparative Assessment of CVD Diamond Manufacturing Technology and Economics" in Synthetic Diamond: Emerging CVD Science and Technology, Edited by Spear, K.E.; Dismuskes, J.P. John Wiley \& Sons, Inc., N.Y., p. 5811994.

2. Trava-Airoldi, V.J.; Corat, E.J.; Baranauskas, V. "Diamond Chemical Vapor Deposition: Emerging Technol- ogy for Tooling Applications, on Advanced Ceramics for Cutting Toll Applications, Editor: Dr. Jim Low, Trans Tech Publications-Switzerland, p. 195. 1997.

3. Trava-Airoldi, V.J.; Corat, E.J.; Ferreira, N.G.; Leite, N.F. "CVD-Diamond: An Overview of Research and Development at INPE", Brazilian Journal of Phisics, v. 27A, p. 88, 1997.

4. Trava-Airoldi, V.J.; Moro, J.R.; Corat, E.J.; Goulart, E.C.; Silva, A.P.; Leite, N.F. "Cylindrical CVD Diamond as a High Performance Small Abrading Device", Surface Coating and Technology, v. 108-109, p. 437-441, 1998.

5. Trava-Airoldi, V.J.; Corat, E.J.; Moro, J.R. "CVD-Diamond Tools and its Uses, Deposited at INPI at the provisory number, INPI0000/01.

6. Zhang, S.; Xie, H.; Zeng, X.; Hing, P. Surface and Coatings Technology, v. 122, p. 219, 1999.

7. Nesladek, M.; Spinnewyn, J.; Asinari, C.; Lebout, R.; Lorent, R. Diamond Relat. Mater., v. 3, p. 98, 1993.

8. Saijo, K.; Yagi, M.; Shibuki, K.; Takatsu, S. Surf. Coat. Technol., v. 43/44, p. 30, 1990.

9. Borges, C.F.M.; Moisan, M.; Roy, F. Method for Producing a High Adhesion Thin Film of Diamond on a FeBased Substrate, US Patent n. 5, v. 759, p. 623, 1998.

10. Saito, K.; Asada, Y.; J. Phys. F, v. 17, p. 2273, 1987.

11. Bredell, L.J.; Van Der Berg, N.G.; Surf. Coat. Technol., v. 104, p. 118, 1998.

12. Braun, M. Nuclear Instruments \& Methods in Physics Research B, v. 59, Part 2, p. 914, 1991. 